OPEN ACCESS

Edited by:

Morten Omholt Alver,

Norwegian University of Science and Technology, Norway

Reviewed by:

Concetta Maria Messina,

University of Palermo, Italy

Tanja Segvic-Bubic,

Institute of Oceanography

and Fisheries (IZOR), Croatia

*Correspondence:

Kilian Toledo-Guedes ktoledo@ua.es

Specialty section:

This article was submitted to

Marine Fisheries, Aquaculture

and Living Resources,

a section of the journal

Frontiers in Marine Science

Received: 01 March 2021

Accepted: 03 June 2021

Published: 01 July 2021

Citation:

Toledo-Guedes K, Brito A and Garcia de Leaniz C (2021) Phenotypic

Convergence in Sea Bass (Dicentrarchus labrax) Escaping From Fish Farms: The Onset of Feralization?

Front. Mar. Sci. 8:674635.

doi: 10.3389/fmars.2021.674635

\section{Phenotypic Convergence in Sea Bass (Dicentrarchus labrax) Escaping From Fish Farms: The Onset of Feralization?}

\author{
Kilian Toledo-Guedes ${ }^{1,2 *}$, Alberto Brito ${ }^{2}$ and Carlos Garcia de Leaniz ${ }^{3}$ \\ ${ }^{1}$ Department of Marine Sciences and Applied Biology, University of Alicante, Alicante, Spain, ${ }^{2}$ Departamento de Biología \\ Animal, Edafología y Geología, Universidad de La Laguna, San Cristobal de La Laguna, Spain, ${ }^{3}$ Centre for Sustainable \\ Aquatic Research (CSAR), Department of BioSciences, Swansea University, Swansea, United Kingdom
}

The impact of fish escaping from fish farms may depend on the extent to which escapees adapt to the natural environment, resemble wild conspecifics, and become feral. Yet, little is known about the process of feralization in marine fish. We examined phenotypic changes in body shape, body condition, and scale growth profiles of sea bass escaping from fish farms in the Canary Islands and quantified the extent to which escapees had diverged from farmed conspecifics. Most feral sea bass had sizes that overlapped with those of farmed fish, indicating that they had escaped throughout the production cycle. However, 29\% of escapees were larger than the maximum size at harvesting, indicating growth in the wild. Analysis of scale growth profiles showed that some escapees had grown in the wild as fast as cultured fish, albeit at more variable growth rates. Feral sea bass tended to converge towards a similar body shape, having more streamlined bodies, lower body condition, and lower hepatosomatic indices (HSI) than fish in cages. Although our study cannot discriminate between phenotypic plasticity and differential mortality of escapees, we interpret phenotypic convergence as the likely result of a period of initial starvation, phenotypic plasticity, and selection against maladapted phenotypes. Our results warn against the risks of rearing sea bass in opennet cages and suggest that sea bass escapees could pose a threat to shallow coastal assemblages, particularly in areas where the species is not naturally found.

Keywords: feralization, domestication, morphometrics, sea bass, fish scales, growth profiles

\section{INTRODUCTION}

Not all aquaculture escapees survive and reproduce in the wild, but some do, and minimizing their impact on wild fish has become an issue of global concern (Naylor et al., 2005). Yet, what makes some aquaculture escapees survive and others die has been little studied, which is surprising since the impact of escapees will likely depend on the extent to which they can survive and adapt to natural conditions, i.e., become feral.

Predicting establishment success of fish escaping from fish farms is not without difficulties (Bekkevold et al., 2006; DeVaney et al., 2009; Consuegra et al., 2011), but it has been suggested that 
phenotypic plasticity-i.e., the production of alternative phenotypes in response to environmental change (WestEberhard, 1989), is a trait that may facilitate feralization (Valiente et al., 2010) because plastic individuals should have more opportunities to adapt to changing conditions and survive (Smith, 2009). Plasticity in fish can be substantial (Smith and Skúlason, 1996; Garcia de Leaniz et al., 2007), though the underlying mechanisms are not well understood. Most studies of plasticity in fish have addressed changes caused by artificial rearing during the process of domestication. Domestication tends to result in large phenotypic variation because, as Darwin (1875) first noted, artificial selection tends to produce extreme phenotypes that can persist under favorable (relaxed natural selection) conditions in captivity (Trut et al., 2009). Indeed, one of the defining traits of domesticated organisms is that they tend to exhibit morphological and physiological variations never seen in the wild (Balon, 2004; Teletchea and Fontaine, 2012). For example, European sea bass (Dicentrarchus labrax) undergo significant changes during domestication, including changes in body shape (Corti et al., 1996; Loy et al., 2000; Costa et al., 2010), swimming performance (Claireaux et al., 2006; Koumoundouros et al., 2009), muscle growth dynamics (Ayala et al., 2003), salinity tolerance (Varsamos et al., 2002), and sex ratio (Navarro-Martín et al., 2009). In contrast, very little is known about how domesticated fish adapt to the wild and become feral.

Fish escaping from aquaculture facilities can be expected to undergo changes in phenotypic traits during feralization (the process of domestication in reverse; Price, 2002; Zeder, 2012) and these can provide cues about the differential response of fish to artificial and natural selection. Such information will be useful for mitigating the impacts of aquaculture escapes because improvements in the adaptation of fish to captivity (domestication) should also translate into loss of fitness in the wild. In general, domestication is expected to increase phenotypic diversity by allowing the survival of extreme phenotypes that would not normally survive in the wild, while feralization is expected to result in phenotypic convergence by selecting some optima on behaviors and body plan (Trut et al., 2009; Zeder, 2012).

Few studies have addressed feralization in fish, and those which done so have tended to concentrate on salmonids (Valiente et al., 2010; Consuegra et al., 2011) or have compared different traits between wild and cultured fish [e.g., body, otholits and escales morphometry, genetic differences, stable isotopes, heavy metals, among others; reviewed in Arechavala-Lopez et al. (2013)]. Although wild vs. hatchery fish comparisons are useful because they allow the detection of escapees (e.g., Schröder and Garcia de Leaniz, 2011; Arechavala-Lopez et al., 2012a,b), they do not shed much light on feralization per se because they are comparing what are essentially different fish. A better approach would be to compare farmed fish before and after they escape through mark and recapture experiments. However, very little success has been achieved in these experiments, since the number of recaptured individuals is usually very low, and the costs of an extensive mark and recapture program is often a barrier (Dempster et al., 2018). Thus, we capitalized on the accidental escape of sea bass in the coastal waters off the Islands of Tenerife and La Palma (Canary Islands, Spain), where the species is not naturally found (Brito et al., 2002), but where sea bass escape regularly (González-Lorenzo et al., 2005). Some of these escapees are able to survive and feed on local trophic resources and this has resulted in a population of feral D. labrax in coastal waters off the islands of La Palma and Tenerife that is maintained through the regular influx of new escapees (Toledo-Guedes et al., 2009, 2012). Recent and old escapees cohabit in the wild and this allowed us to make comparisons among individuals from a common farm origin that had spent different times at liberty. Thus, we examined the process of feralization by quantifying the phenotypic changes that are displayed by sea bass when they escape into the wild.

\section{MATERIALS AND METHODS}

\section{Study Site and Sampling Method}

The study was carried out in the Canary Islands (Figure 1). Fish were sampled in two of the islands where sea bass regularly escape from open-net fish cages: Tenerife and La Palma (Toledo-Guedes et al., 2009). We spear-caught or hand-netted 73 feral sea bass in the vicinity of two fish farms (11 in La Palma and 66 in Tenerife). For comparisons, 20 cultured sea bass were also sampled at the same time (10 in each island).

Farmed fish are selected for fast growth and generally fed in excess in captivity. We therefore examined three phenotypic traits directly affected by growth and which are likely to change during the transition from captive to natural environments: growth rate-based in the analysis of growth rings (circuli) found on fish scales, body condition-inferred from the hepatosomatic index and the condition factor, and body shape-derived from measurements of multiple morphological traits obtained through digital photography. Table 1 shows sample size, mean length and weight of the fish involved in each analysis.

\section{Scale Growth Analysis}

We examined the pattern of ring deposition (circuli) in the scales of cultured fish $(n=20)$ and escapees $(n=52)$ to derive comparative measures of growth. For each individual, five to ten scales were collected from a standardized region below the dorsal fin and above the lateral line. Three of the best scales, having clear, non-regenerated nuclei, were chosen for analysis. To avoid artifacts caused by excessive early scale erosion, we excluded scales with distances from the focus to the first circulus larger than $500 \mu \mathrm{m}$. Impressions were made on cellulose acetate slides using a pressure roller and then scanned with a Minolta MS 6000 microfiche reader at 23-50 magnifications and saved as a high-resolution TIFF files, as in Kuparinen et al. (2009). Starting from the scale focus, the position of each growth circuli was digitized using ImageJ (Abràmoff et al., 2004) in order to estimate inter-circuli spacing and scale growth increments. As scales in sea bass are ctenoid and do not have a single longest axis, we used scale dimensions, rather than estimates of backcalculated body size, to compare growth among individuals. Using scale dimensions for comparing growth assumes that body 

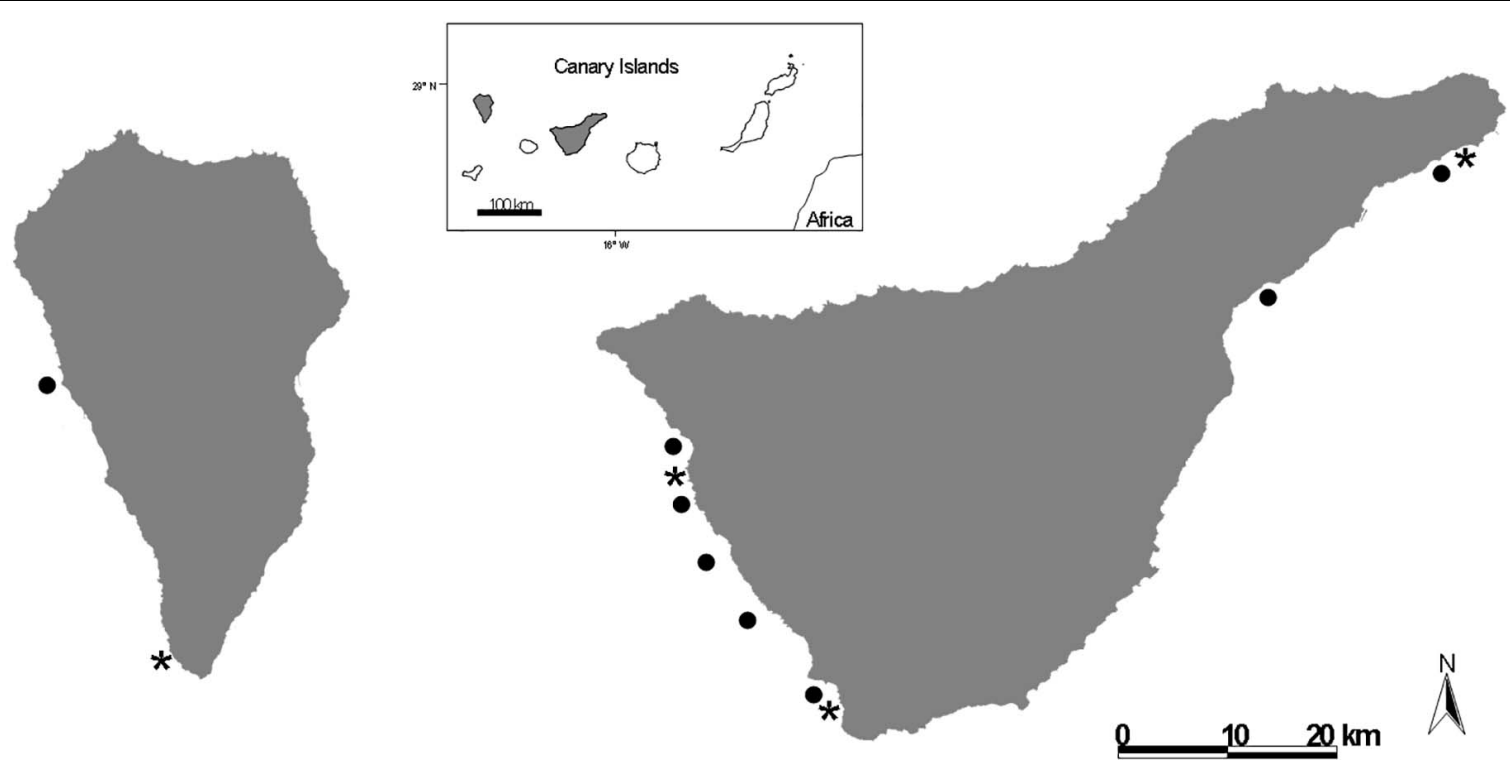

FIGURE 1 | Location of sea bass farms $(\bullet)$ and sampling sites $(\boldsymbol{\star})$ in the coastal waters of the islands of La Palma and Tenerife (Canary Islands, Spain).

TABLE 1 | Summary of the sample size (n), mean \pm SD fork length in $\mathrm{cm}(\mathrm{FL})$ and mean \pm SD total weight in $\mathrm{g}(\mathrm{W})$ for each analysis performed in this study.

\begin{tabular}{|c|c|c|c|c|c|}
\hline \multirow[b]{2}{*}{ Origin } & \multirow[b]{2}{*}{ Location } & \multicolumn{2}{|c|}{ Scale growth/body condition } & \multicolumn{2}{|c|}{ Body morphology/discriminant function } \\
\hline & & Fork length/weight & $n$ & Fork length/weight & $n$ \\
\hline \multirow[t]{2}{*}{ Feral } & Tenerife & $40.2 \pm 11.6 / 1,113 \pm 890$ & 41 & $41.3 \pm 11.3 / 1,109 \pm 856$ & 28 \\
\hline & La Palma & $26.1 \pm 5.6 / 237 \pm 167$ & 11 & $26.1 \pm 5.6 / 237 \pm 167$ & 11 \\
\hline \multirow[t]{2}{*}{ Cultured } & Tenerife & $33.3 \pm 2.3 / 561 \pm 118$ & 10 & $33.3 \pm 2.3 / 561 \pm 118$ & 10 \\
\hline & La Palma & $35.7 \pm 1.4 / 579 \pm 112$ & 10 & $35.7 \pm 1.4 / 579 \pm 112$ & 10 \\
\hline
\end{tabular}

size is proportional to scale size (Francis, 1990), but avoids introducing additional errors resulting from measurements of body size taken in the field.

The Pearson correlation coefficient was used to estimate the strength of association between scale radius and body size, and a paired $t$-test was used to compare the original scales and their acetate impressions in order to quantify potential bias resulting from pressure from the hand roller. To ascertain precision in scale analysis, we measured the scale radii of 29 individuals twice in a double-blind fashion and calculated the intra-class correlation coefficient ( $\alpha$-Cronbach) as a measure of repeatability.

Farmed and feral fish may differ on the spacing between growth rings, as well as on the size of the scale nucleus (focus), and the variation in inter-circuli spacing. We therefore examined the following scale metrics in sea bass: radius from the scale focus to the first readable circulus $(R)$, as well as the means $(M)$ and standard deviations (SD) of the distance between consecutive growth circuli (inter-circuli spacing) for the whole scale $\left(M_{\text {tot }}\right)$, the first twenty circuli $\left(M_{20 \text { ini }}\right)$, and the last twenty circuli $\left(M_{20 l a s t}\right)$. Growth profiles were obtained by plotting circuli number against cumulative scale size and ordinary least regression was then used to determine growth slopes $(B)$ for each specimen.

\section{Body Condition Indices}

We examined two integrative indicators of body condition that may be expected to change when farmed fish escape into the wild: the hepatosomatic index [HSI = liver weight/total weight] and Fulton's condition factor $[K=100 \times$ total weight/(total length $)^{3}$ ].

\section{Variation in Body Morphology}

To examine the extent of body shape divergence associated with feralization in sea bass we took standardized photographs of 39 escapees and 20 cultured fish from each island with a Nikon Coolpix 5400 digital camera. The positions (x, y co-ordinates) of 25 landmarks were digitized using Image J and fifteen distances between selected landmarks were then calculated (Figure 2) using the program PAST v. 2.16 (Hammer et al., 2001).

\section{Statistical Analysis}

Prior to analysis, all morphometric measurements were size adjusted using the "allometric vs. standard" method proposed by Elliott et al. (1995) and implemented in PAST 2.15 (Hammer et al., 2001). We employed a permutational multivariate analysis of variance (PERMANOVA, McArdle and Anderson, 2001) with fish origin (escape vs. farmed) as a fixed factor and location (Tenerife vs. La Palma) as an orthogonal 


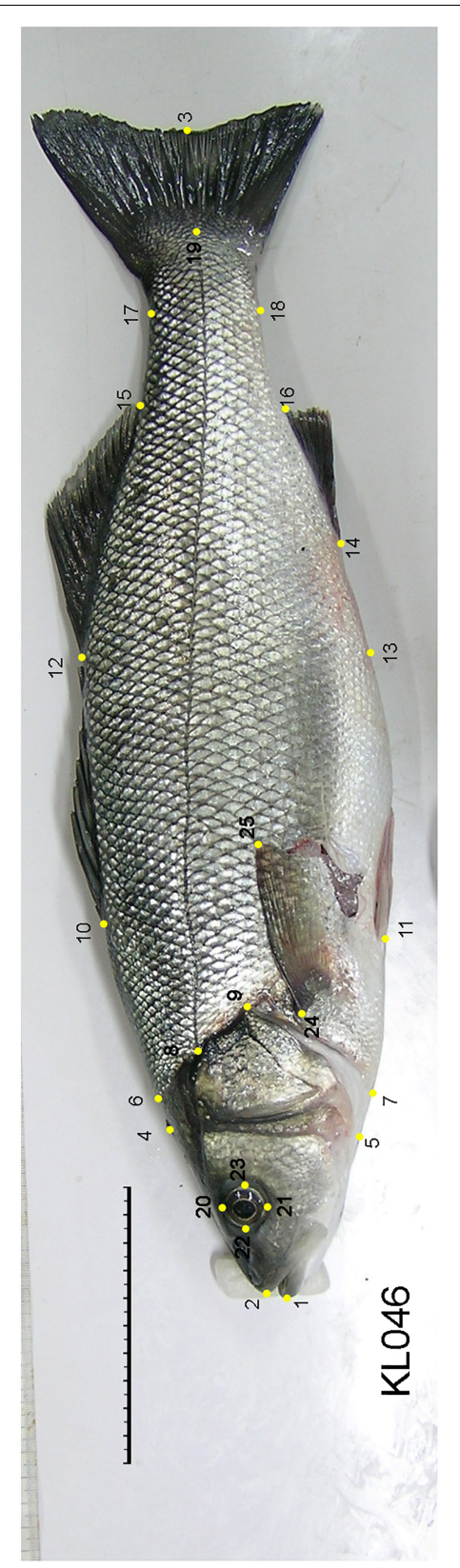

FIGURE 2 | Landmarks used in the morphometric analysis of sea bass: fork length (1-3), standard length (1-19), head length (1-9), lateral line length (8-19), first head depth (4-5), second head depth (6-7), first body depth (10-11), second body depth (12-13), third body depth (15-16), peduncle depth (17-18), second dorsal length (12-15), anal fin length (14-16), orbital depth (20-21), orbital length (22-23), and pectoral length (24-25).

random factor, to examine variation in scale growth profiles and body shape between cultured fish and escapees based on Euclidean distances and 10,000 permutations. Pairwise differences in traits between groups were tested for significance by Bonferroni-corrected probabilities. Although morphometric traits were size-adjusted, body size can still account for a significant amount of morphometric variation (Loy et al., 2000),

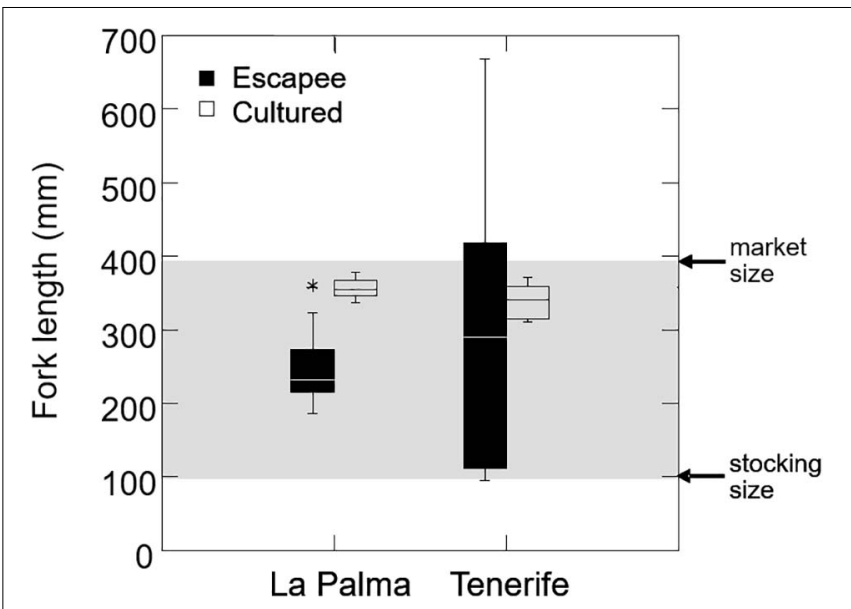

FIGURE 3 | Size distribution of cultured and feral sea bass in each island. Gray area shows the typical size interval of sea bass during culture in sea cages, determined by the typical size at stocking (c. $100 \mathrm{~mm}$ ) and the market size (c. $400 \mathrm{~mm})$.

and large fish are also more likely to show some scale regeneration than smaller ones (Fritsch, 2005). Hence, we included fork length (FL) as a covariate in our analysis to account for differences in body size between farmed fish and escapees. Principal component analyses (PCA) with varimax rotation were performed on morphometric and scale traits and all PCAs with eigenvalues $>1.00$ were considered to be influential (Chatfield and Collins, 1983). A discriminant function analysis (DFA) was undertaken using the "leave-one-out classification" to assess the success of size-adjusted morphometric measurements and scale growth profiles in discriminating between cultured fish and escapees from the two islands. Differences in body condition and hepatosomatic index between feral and farmed fish were tested by paired $t$-tests at both islands. We used PRIMER 6+, PAST 2.15 and SPSS 17.0 for statistical analyses.

\section{RESULTS}

\section{Size Distribution of Escapees}

Escapees had body sizes that covered the full-size range found in culture (Figure 3), ranging from the size at which fish were typically stocked in sea cages $(c .100 \mathrm{~mm})$ to the size at which they were normally harvested (c. $400 \mathrm{~mm}$ ). This suggests that escape events can occur at any time during the production cycle. We also found 21 escapees (representing 29\% of escaped fish, and all restricted to Tenerife) that had body sizes outside the upper $95 \%$ confidence interval of fish found at cages (i.e., $>410 \mathrm{~mm}$ ), and which are indicative of somatic growth in the wild. In one extreme case, an escapee had a size of $667 \mathrm{~mm}$ and an estimated age of 7.5 years. Given that farmed sea bass are typically marketed after 15 months, this would indicate that this fish had been growing in the wild for at least 6.3 years. 


\section{Scale Growth Profiles of Farmed Fish and Escapees}

There was a small but significant shrinkage of scale radius due to the acetate impression (matched $t_{28}=-2.46, P=0.021$ ) but this amounted to only $1.24 \%$ of the scale size and was unlikely to bias the results, as impressions were made of all scales. More importantly, repeatability in measuring scale radius was very high $(\alpha$-Cronbach $=1.00)$, and FL was strongly correlated to both scale radius $(r=0.90, P<0.001)$ and number of growth circuli ( $r=0.98, P<0.001)$ suggesting that scale measurements can be used to reconstruct changes in body size in sea bass.

Matched comparisons of scale growth increments between circuli numbers 20-40 (corresponding to a body size of $<90 \mathrm{~mm}$, before fish were stocked in the cages) and circuli numbers 100120 (corresponding to a body size of 171-199 mm, after c. 1 year of growth) revealed very different patterns of growth between farmed fish and escapees (Figure 4). Thus, farmed fish (mean scale increment $=0.05 \mathrm{~mm}, \mathrm{SD}=0.03$ ) grew on average more than twice as fast than escapees (mean scale increment $=0.02 \mathrm{~mm}, \mathrm{SD}=0.04$ ) during this period ( $\left.t_{66}=-2.46, P=0.016\right)$, though some escapees showed evidence of compensatory growth (as revealed by the frequency of fish moving up the size rank, Marco-Rius et al., 2012) and ended up growing as fast as farmed fish did.

Principal component analysis showed that three components explained $74 \%$ of the total variability in scale growth patterns and served to discriminate between farmed fish and escapees (Table 2). Results of univariate PERMANOVA indicated that four variables were significantly higher in escapees than in farmed fish at $\alpha=0.05$ : the mean inter-circuli spacing for the first twenty circuli of the scale $\left(M_{20 \mathrm{ini}}\right)$, the radius from the scale focus (nucleus) to the first readable circulus $(R)$, and the variability in inter-circuli spacing for the first twenty circuli $\left(\mathrm{SD}_{20 \mathrm{ini}}\right)$ and the whole scale $\left(\mathrm{SD}_{\text {tot }}\right)$. DFA indicated that $60 \%$ of farmed fish in Tenerife and 70\% of farmed fish in La Palma were correctly classified to their location of origin based on scale growth patterns. However, escapees were more similar in scale growth profiles than cultured fish and could not be assigned to location of capture with any confidence: only 59\% of escapees from Tenerife and 36\% of escapees from La Palma were assigned to the correct island, suggesting that there was phenotypic convergence in the wild.

\section{Condition Factor and Hepatosomatic Index}

Sea bass had significantly lower hepatosomatic indices (HSI) in the wild than in the cages at both locations (Tenerife $t_{34.030}=-4.80, P<0.001$; La Palma $\left.t_{19}=-6.76, P<0.001\right)$. Body condition factor was also significantly lower amongst escapees than among farmed fish in one of the islands (Tenerife $\left.t_{37.718}=-9.28, P<0.001\right)$ but not in the other (La Palma $\left.t_{19}=0.40, P=0.692\right)$.

\section{Morphometric Analysis}

Farmed and feral sea bass were significantly different in morphological traits (PERMANOVA pseudo- $F=7.056$,

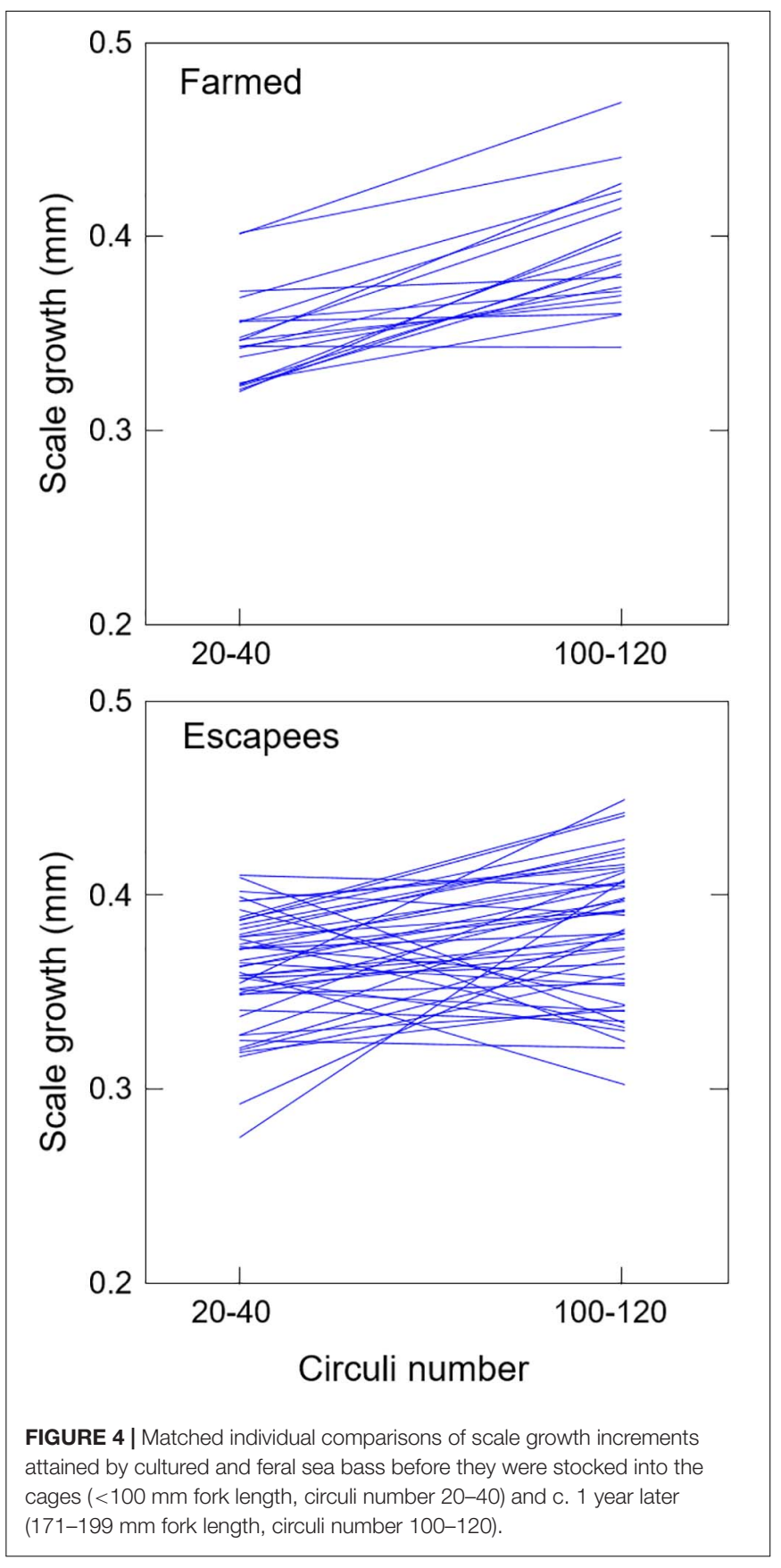

$P<0.001)$. Discriminant plots reveal a greater separation in body shape between cultured stocks than between escapees, which tended to converge on a similar morphotype at the two locations (Figure 5). Such convergence in body shape of escapees is reflected in the different classification accuracies of the discriminant function. Thus, while farmed fish were correctly assigned to their island of origin in $100 \%$ (Tenerife) and $80 \%$ of cases (La Palma), correct classification of escapees decreases to $68 \%$ (Tenerife) and 55\% (La Palma). Overall, the accuracy of the morphometric analysis in discriminating between farmed fish and escapees was $81.4 \%$ with the leave-one-out procedure. 
TABLE 2 | Principal component analysis of scale growth profiles and their mean values $\left(\times 10^{2}\right)$ for cultured and feral (escapee) sea bass.

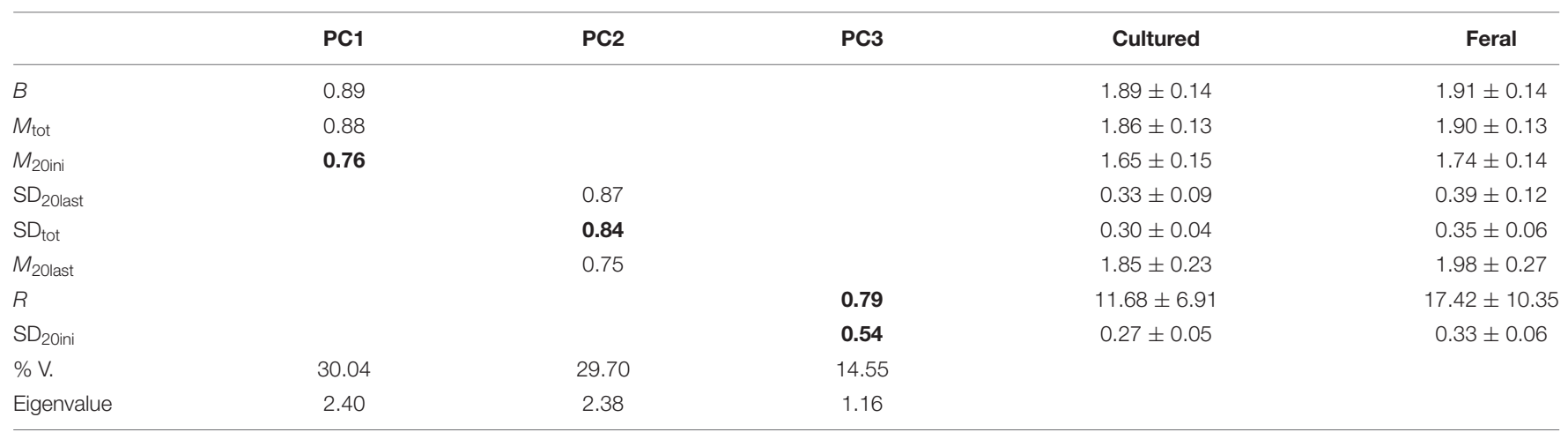

Morphometric traits showing significant $(P<0.05)$ differences between farmed and feral fish according to PERMANOVA are shown in bold.

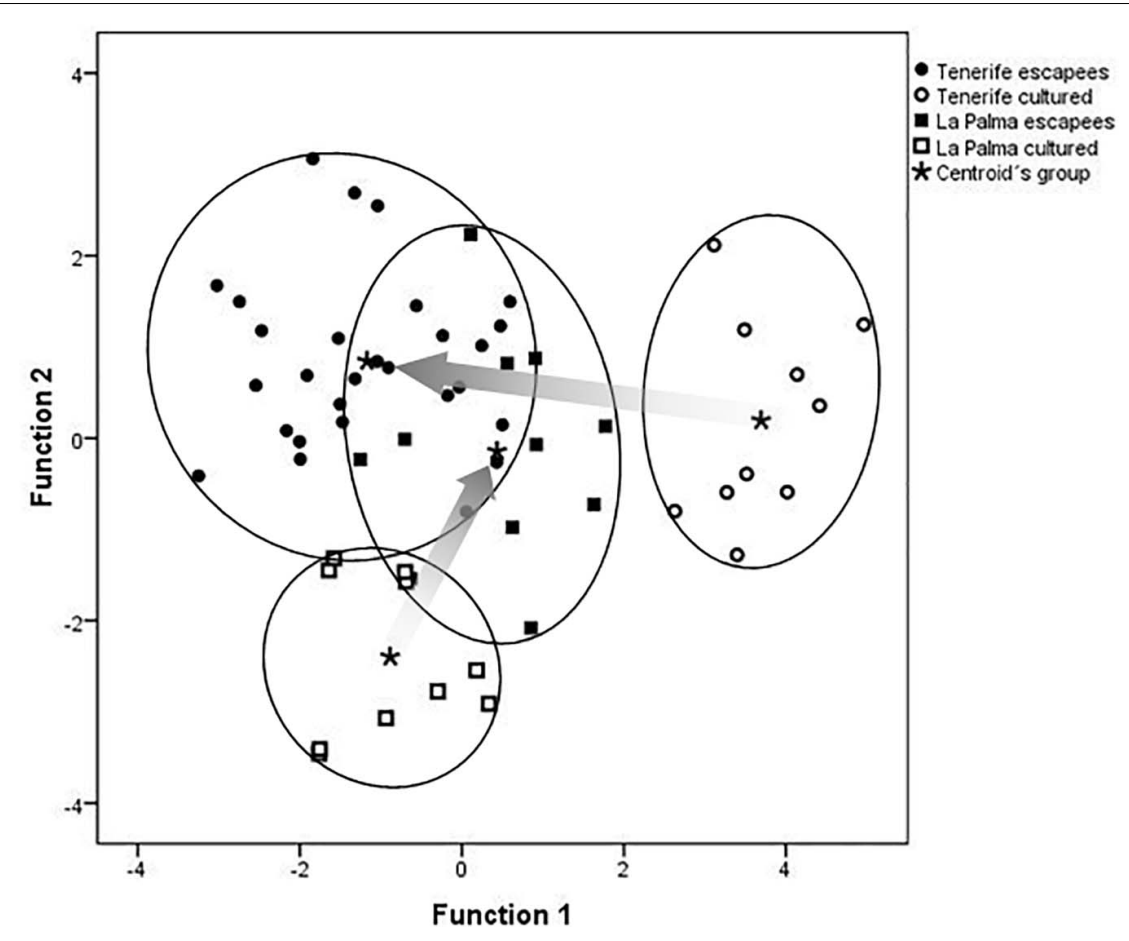

FIGURE 5 | Discriminant plots based on size-adjusted morphometric measurements of cultured and feral sea bass (escapees). Group centroids are indicated by asterisks and inferred phenotypic shifts during feralization are indicated by arrows extending from farms to feral centroids in each island.

Pairwise PERMANOVA comparisons revealed significant differences in morphometric traits between the groups recognized in the discriminant plots (Table 3). Thus, while there were highly significant differences in the body shape of cultured fish between farms $(P<0.001)$, no differences were detected in the body shape of escapees between locations $(P>0.05)$. Additionally, there were significant differences between cultured fish and escapees in Tenerife $(P<0.01)$ and nearly so in La Palma after applying a conservative Bonferroni-correction $(P=0.079)$. A combination of four principal components explained $79.5 \%$ of the total variation of size-adjusted morphological variables. The first extracted component accounted for variables related to body depth and head length and showed that escapees were generally more streamlined (lower body depth) and had longer heads than farmed fish (Table 4). The second principal component was formed mainly by variables related to body size and orbital depth, which were both higher among escapees than among farmed fish. The third component accounted for variation in head depths and showed that farmed fish have deeper heads than escapees. Finally, the fourth component captured variability in the length of the anal and dorsal fins, which were larger in farmed fish.

\section{DISCUSSION}

Our study reveals that sea bass escaping from fish farms undergo significant phenotypic changes in the wild and tend to converge toward a more similar phenotype compared to farmed 
TABLE 3 | Matrix of pairwise PERMANOVA comparisons of body shape between cultured and feral sea bass at the two study locations.

\begin{tabular}{lccc}
\hline Group & Feral - TF & Feral- LP & Cultured - LP \\
\hline Feral - LP & 1.000 & - & - \\
Cultured- LP & $\mathbf{0 . 0 1 9}$ & 0.079 & - \\
Cultured- TF & $\mathbf{0 . 0 0 2}$ & $\mathbf{0 . 0 0 1}$ & $\mathbf{0 . 0 0 1}$ \\
\hline
\end{tabular}

TF, Tenerife; LP, La Palma.

Shown are Bonferroni-corrected pairwise probabilities (significant values in bold) derived from 10,000 permutations (pseudo- $F=4.11, P<0.001$ ).

conspecifics. We found clear differences in body shape between cultured and escaped sea bass, with escapees having smaller body depths, and more streamlined bodies compared to the fatter, more rounded body shape of farmed fish. Significant differences were also found on the relative sizes of the anal and dorsal fins, which were smaller and less variable in feral fish. Similar changes have been reported for a range of other species and serve to highlight the nature of feralization in fish, which is thought to be guided by a shift in food regime, non-random survival of maladapted phenotypes, and morphological changes (Lorenzen et al., 2012).

The fact that the body shape of feral sea bass differed greatly from that of farmed fish (Table 3 and Figure 5) may be indicative of high plasticity, as body shape is very dependent on local rearing conditions on this species. For example, sea bass can show marked differences in body shape among sea cages, even when fish originate from the same breeders (Costa et al., 2010), apparently due to variation in temperature and rearing densities which affect body shape indirectly through their effects on growth and swimming activity. Studies on other species have also documented the strong effects that food regime and swimming activity can have on body shape (Pakkasmaa and Piironen, 2001; Marcil et al., 2006).
Morphometric traits in fish are greatly affected by rearing conditions, environmental complexity, and food source (Wimberger, 1992; Loy et al., 2000; Hegrenes, 2001; Costa et al., 2010) and these can differ markedly between fish cages and the natural environment. An unpredictable food supply, presence of predators, and a reduction in densities of conspecifics are amongst the main changes faced by farmed fish when they escape into the wild (Toledo-Guedes et al., 2014). In this sense, the more streamlined body shape of feral fish should reduce swimming costs and improve swimming performance in the wild (Enders et al., 2004), while the larger anal and dorsal fins of cultured fish may have resulted from departures from isometric growth under crowded conditions in captivity.

We found a significant decrease in the hepatosomatic indexand in many cases also in the condition factor of escapees $(P<0.001)$, which may reflect a response to food deprivation and trophic adjustment following the escape. A period of slow growth in the first part of the scale followed by a period of faster growth is also evident in the scales of some escapees (Figure 4), which may be indicative of compensatory growth (i.e., fast growth following a period of growth depression typically caused by food deprivation (Ali et al., 2003; Marco-Rius et al., 2012, 2013). Compensatory growth has been reported in sea bass before (Sahin et al., 2000; Dosdat et al., 2003; Rubio et al., 2010; Chatzifotis et al., 2011), although the underlying mechanisms remain poorly understood. It is likely that in this case, compensatory growth may have been the result of trophic adjustment following escape into the wild, as suggested also by changes in condition indices.

Trophic adjustment appears in any case to have been shortlived, at least for those escapees that survived in the wild, because feral sea bass showed similar values of total intercirculi spacing and scale growth slopes than farmed fish. Under the assumption that scale size is positively related to somatic

TABLE 4 | Principal component analysis for size-adjusted morphometric traits and their mean values $\left(\times 10^{3}\right)$, for cultured and feral (escapee) sea bass.

\begin{tabular}{|c|c|c|c|c|c|c|}
\hline Morphometric trait & PC1 & PC2 & PC3 & PC4 & Cultured & Feral \\
\hline 2nd Body depth & 0.92 & & & & $4.98 \pm 0.06$ & $4.91 \pm 0.08$ \\
\hline 1st Body depth & 0.80 & & & & $4.98 \pm 0.05$ & $4.97 \pm 0.06$ \\
\hline Peduncle depth & 0.77 & & & & $3.93 \pm 0.04$ & $3.92 \pm 0.08$ \\
\hline 3rd Body depth & 0.72 & & & & $4.21 \pm 0.07$ & $4.16 \pm 0.12$ \\
\hline Head length & -0.77 & & & & $5.05 \pm 0.06$ & $5.13 \pm 0.08$ \\
\hline Orbital length & -0.60 & & & & $2.95 \pm 0.11$ & $2.98 \pm 0.10$ \\
\hline Standard length & & 0.84 & & & $6.49 \pm 0.03$ & $6.51 \pm 0.12$ \\
\hline Lateral line length & & 0.84 & & & $6.18 \pm 0.04$ & $6.18 \pm 0.09$ \\
\hline Fork length & & 0.82 & & & $6.62 \pm 0.03$ & $6.63 \pm 0.14$ \\
\hline Orbital depth & & -0.78 & & & $2.88 \pm 0.12$ & $2.97 \pm 0.12$ \\
\hline Pectoral length & & -0.61 & & & $4.46 \pm 0.06$ & $4.50 \pm 0.08$ \\
\hline 1st Head depth & & & 0.91 & & $4.60 \pm 0.07$ & $4.62 \pm 0.05$ \\
\hline 2nd Head depth & & & 0.82 & & $4.71 \pm 0.04$ & $4.69 \pm 0.05$ \\
\hline Anal Fin length & & & & -0.86 & $4.52 \pm 0.05$ & $4.45 \pm 0.11$ \\
\hline 2nd Dorsal length & & & & -0.70 & $4.86 \pm 0.08$ & $4.80 \pm 0.08$ \\
\hline$\%$ Variance & 27.86 & 25.51 & 14.27 & 11.90 & & \\
\hline Eigenvalue & 4.18 & 3.83 & 2.14 & 1.78 & & \\
\hline
\end{tabular}

Numbers in bold indicate significant $(P<0.05)$ morphometric differences according to PERMANOVA. 
growth-an assumption generally upheld in a number of fishes (e.g., Cheung et al., 2007; Marco-Rius et al., 2012) and which appears to be the case also in our study, this would suggest that escapees can grow in the natural environment as fast as farmed fish do in fish cages. Yet, growth of feral sea bass tended to be more variable than in sea cages (as evidenced by the larger standard deviation in inter-circuli spacing; Table 2), which likely reflects the greater unpredictability of trophic resources in the wild, as well as a period of foraging adjustment to natural prey, which has a strong learning component (Brown and Laland, 2003; Olsen and Skilbrei, 2010).

Feralization in sea bass appears to involve a sudden and dramatic shift in food regime and a variable period of starvation, as reported also for sea bream (Arechavala-Lopez et al., 2012c). Food deprivation would result in the mobilization of lipids and subsequent loss of weight, especially hepatic weight (PérezJiménez et al., 2007), as observed in our study. In this sense, the presence of recent escapees is suggested by the existence of several individuals with very high condition factors and high HSI, more similar to those found amongst cultured fish. Indeed, DFA on body shape classified $15 \%$ of feral fish as farmed fish (see overlapped individuals in Figure 5), suggesting that these may have been recent escapees.

We found that feral sea bass had body sizes that extended over the full-size continuum, between the size at which they were stocked in the cages and the size at which they are typically harvested, indicating that sea bass in this region are escaping at all stages during the production cycle, as found for other fish farmed in open net cages (Dempster et al., 2007; Consuegra et al., 2011). A relatively large proportion of escapees (29\%) had body sizes larger than the maximum size at harvesting, which supports the contention that these were fish that had been at liberty for some time and grown in the wild, in some cases for several years. It is possible that such large escapees have had more time to adapt to natural conditions and had therefore diverged more from the farm body template. This would explain why feral sea bass were morphologically more different from farmed fish in Tenerife (where all the large escapees were found) than in la Palma, where all the escapees were below harvest size and thus likely more recent escapees.

We did not conduct a mark and recapture study of individual fish, and cannot therefore discriminate between phenotypic plasticity and selection, although our results are consistent with both. Thus, the observed phenotypic convergence in the wild may be indicative of differential mortality of extreme phenotypes and stabilizing natural selection (Manly, 1985), while the changes observed in the body shape of escapees, most notably a more streamlined body and longer heads may be indicative of phenotypic plasticity (Rogdakis et al., 2011). Intense selection in the wild would explain why we failed to find escapees with marked deformities in the wild (Toledo-Guedes et al., 2009), features that are common among fish in cages and that suggest that deformed sea bass may have sustained elevated mortalities following their escape into shallow coastal waters. Thus, the combination of phenotypic plasticity, intense selection against maladapted phenotypes, and a period of initial starvation give a plausible explanation for the observed results. It must be noted, however, that phenotypic convergence does not necessarily imply adaptive change (Garcia de Leaniz et al., 2007) and that variation among families in their propensity to the escape might have also affected our results.

Sea bass is a particularly plastic species (Corti et al., 1996; Loy et al., 2000; Costa et al., 2010) with environmentally induced sex determination (Vandeputte et al., 2012) and our results suggest that such plasticity may have aided in the feralization process by allowing escapees to adapt quickly to natural conditions. In areas where farmed and wild sea bass coexist (e.g., the Mediterranean), it would be interesting to determine how long it takes for escapees to resemble the wild counterparts. This is something that was outside the scope of our study but that would help to gain valuable insights into the scope for introgression. Although it is not yet known if sea bass escapees have developed self-sustainable populations in the study area (Toledo-Guedes et al., 2012), multiple escapes, high propagule pressure and high plasticity would make this species suitable for establishment off the coastal waters of the Canary Islands. Such concerns stress the need for monitoring plans of open-net cages in aquaculture, particularly when the species being farmed are not naturally found in the region.

\section{DATA AVAILABILITY STATEMENT}

The raw data supporting the conclusions of this article are available upon request from the first author.

\section{ETHICS STATEMENT}

Ethical approval was not required for this study at ULL as no experiments were conducted on live fish, and all morphometric data were collected from dead specimens from a farm or from fish captured by accepted techniques that entail minimum suffering.

\section{AUTHOR CONTRIBUTIONS}

KT-G sampled and carried out laboratory analyses. KT-G and CGL analyzed the data, interpreted and discussed the results, and co-wrote the manuscript. KT-G, CGL, and AB reviewed and edited the manuscript. All authors contributed to the article and approved the submitted version.

\section{FUNDING}

KT-G was funded by a doctoral fellowship from Canary Island Government co-financed by the European Union (FEDER), postdoctoral tenure program Juan de la Cierva Formación 
(FJCI-2014-20100) and Juan de la Cierva Incorporación (IJCI-2017-34174). Funded by Project GLORiA “GLObal change Resilience in Aquaculture," supported by the Biodiversity Foundation of the Spanish Ministry for the Ecological Transition and Demographic Challenge, through the Pleamar Program and co-financed by the European Maritime and Fisheries Fund (EMFF). It is also part of the LIFE IP INTEMARES project "Integrated, innovative and participatory management of the Natura 2000 Network in the Spanish marine environment."

\section{REFERENCES}

Abràmoff, M. D., Magalhaes, P. J., and Ram, S. J. (2004). Image Processing with ImageJ. Biophotonics Int. 11, 36-42.

Ali, M., Nicieza, A., and Wootton, R. J. (2003). Compensatory growth in fishes: a response to growth depression. Fish Fish. 4, 147-190. doi: 10.1046/j.1467-2979. 2003.00120.x

Arechavala-Lopez, P., Fernandez-Jover, D., Black, K. D., Ladoukakis, E., BayleSempere, J. T., Sanchez-Jerez, P., et al. (2013). ). Differentiating the wild or farmed origin of Mediterranean fish: a review of tools for sea bream and sea bass. Rev. Aquac. 5, 137-157. doi: 10.1111/raq.12006

Arechavala-Lopez, P., Sanchez-Jerez, P., Bayle-Sempere, J. T., Sfakianakis, D. G., and Somarakis, S. (2012a). Discriminating farmed gilthead sea bream Sparus aurata and European sea bass Dicentrarchus labrax from wild stocks through scales and otoliths. J. Fish Biol. 80, 2159-2175. doi: 10.1111/j.1095-8649.2012. 03236.x

Arechavala-Lopez, P., Sanchez-Jerez, P., Bayle-Sempere, J. T., Sfakianakis, D. G., and Somarakis, S. (2012b). Morphological differences between wild and farmed Mediterranean fish. Hydrobiologia 697, 217-231. doi: 10.1007/s10750-0110886-y

Arechavala-Lopez, P., Uglem, I., Fernandez-Jover, D., Bayle-Sempere, J. T., and Sanchez-Jerez, P. (2012c). Post-escape dispersion of farmed seabream (Sparus aurata L.) and recaptures by local fisheries in the Western Mediterranean Sea. Fish. Res. 121-122, 126-135. doi: 10.1016/j.fishres.2012.02.003

Ayala, M. D., López, O., García, A., Abellán, E., Latorre, R., Vázquez, J. M., et al. (2003). Effect of two thermal regimes on the muscle growth dynamics of sea bass larvae, Dicentrarchus labrax L. Anat. Histol. Embryol. 32, 271-275. doi: 10.1046/j.1439-0264.2003.00482.x

Balon, E. K. (2004). About the oldest domesticates among fishes. J. Fish Biol. 65 , 1-27. doi: $10.1111 / \mathrm{j} .0022-1112.2004 .00563 . x$

Bekkevold, D., Hansen, M., and Nielsen, E. (2006). Genetic impact of gadoid culture on wild fish populations: predictions, lessons from salmonids, and possibilities for minimizing adverse effects. ICES J. Mar. Sci. 63, 198-208. doi: 10.1016/j.icesjms.2005.11.003

Brito, A., Pascual, P. J., Falcón, J. M., Sancho, A., and González, G. (2002). Peces de las Islas Canarias: Catálogo Comentado e Ilustrado. La Laguna: Francisco Lemus Editor.

Brown, C., and Laland, K. (2003). Social learning in fishes: a review. Fish Fish. 4, 280-288. doi: 10.1046/j.1467-2979.2003.00122.x

Chatfield, C., and Collins, A. J. (1983). Introduction to Multivariate Analysis. London: Chapman \& Hall.

Chatzifotis, S., Papadaki, M., Despoti, S., Roufidou, C., and Antonopoulou, E. (2011). Effect of starvation and re-feeding on reproductive indices, body weight, plasma metabolites and oxidative enzymes of sea bass (Dicentrarchus labrax). Aquaculture 316, 53-59. doi: 10.1016/j.aquaculture.2011.02.044

Cheung, C. H. Y., Chaillé, P. M., Randall, D. J., Gray, J. S., and Au, D. W. T. (2007). The use of scale increment as a means of indicating fish growth and growth impairment. Aquaculture 266, 102-111. doi: 10.1016/j.aquaculture.2007.02.036

Claireaux, G., Couturier, C., and Groison, A.-L. (2006). Effect of temperature on maximum swimming speed and cost of transport in juvenile European sea bass (Dicentrarchus labrax). J. Exp. Biol. 209, 3420-3428. doi: 10.1242/jeb.02346

Consuegra, S., Phillips, N., Gajardo, G., and Garcia de Leaniz, C. (2011). Winning the invasion roulette: escapes from fish farms increase admixture and facilitate establishment of non-native rainbow trout. Evol. Appl. 4, 660-671. doi: 10.1111/ j.1752-4571.2011.00189.x

\section{ACKNOWLEDGMENTS}

We would like to thank Tamia Brito, coordinator of La Palma MPA, Carlos Sangil from La Palma World Biosphere Reserve, and Tomás Sentís from Cabildo de La Palma. We would also like to thank Pablo Arechavala for assistance in morphometric analysis, to Antonio Concepción (Tronchu), Luis Díaz, Gustavo González, and Jaume Mora for valuable help during sampling and to Sonia Consuegra for useful comments on the manuscript.

Corti, M., Loy, A., and Cataudella, S. (1996). Form changes in the sea bass, Dicentrarchus labrax (Moronidae: Teleostei), after acclimation to freshwater: an analysis using shape coordinates. Environ. Biol. Fish. 47, 165-175. doi: 10.1007/bf00005039

Costa, C., Vandeputte, M., Antonucci, F., Boglione, C., Menesatti, P., Cenadelli, S., et al. (2010). Genetic and environmental influences on shape variation in the European sea bass (Dicentrarchus labrax). Biol. J. Linn. Soc. 101, 427-436. doi: 10.1111/j.1095-8312.2010.01512.x

Darwin, C. (1875). The Variation of Animals and Plants under Domestication, 2nd Edn, Vol. 2. London: John Murray.

Dempster, T., Arechavala-Lopez, P., Barrett, L. T., Fleming, I. A., Sanchez-Jerez, P., and Uglem, I. (2018). Recapturing escaped fish from marine aquaculture is largely unsuccessful: alternatives to reduce the number of escapees in the wild. Rev. Aquac. 10, 153-167. doi: 10.1111/raq.12153

Dempster, T., Moe, H., Fredheim, A., Jensen, Ø., and Sanchez-Jerez, P. (2007). Escapes of marine fish from sea-cage aquaculture in the Mediterranean Sea: status and prevention. CIESM Workshop Monogr. 32, 55-60.

DeVaney, S. C., McNyset, K. M., Williams, J. B., Peterson, A. T., and Wiley, E. O. (2009). A tale of four "carp": invasion potential and ecological niche modeling. PLoS One 4:e5451. doi: 10.1371/journal.pone.0005451

Dosdat, A., Person-Le Ruyet, J., Covès, D., Dutto, G., Gasset, E., Le Roux, A., et al. (2003). Effect of chronic exposure to ammonia on growth, food utilisation and metabolism of the European sea bass (Dicentrarchus labrax). Aquat. Living Resour. 16, 509-520. doi: 10.1016/j.aquliv.2003.08.001

Elliott, N. G., Haskard, K., and Koslow, J. A. (1995). Morphometric analysis of orange roughy (Hoplostethus atlanticus) off the continental slope of southern Australia. J. Fish Biol. 46, 202-220. doi: 10.1111/j.1095-8649.1995. tb05962.x

Enders, E. C., Boisclair, D., and Roy, A. G. (2004). Differences in the energetic cost of swimming in turbulent flow between wild, farmed and domesticated juvenile Atlantic salmon Salmo salar. J. Fish Biol. 65:317. doi: 10.1111/j.0022-1112.2004. 0559h.x

Francis, R. I. C. C. (1990). Back-calculation of fish length: a critical review. J. Fish Biol. 36, 883-902. doi: 10.1111/j.1095-8649.1990.tb05636.x

Fritsch, M. (2005). Traits Biologiques et Exploitation du bar Commun Dicentrarchus labrax (L.) dans les Pêcheries Françaises de la Manche et du golfe de Gascogne. Ph.D. thesis. Brest: Université de Bretagne occidentale.

Garcia de Leaniz, C., Fleming, I. A., Einum, S., Vespoor, E., Jordan, W. C., Consuegra, S., et al. (2007). A critical review of adaptive genetic variation in Atlantic salmon: implications for conservation. Biol. Rev. 82, 173-211. doi: 10.1111/j.1469-185x.2006.00004.x

González-Lorenzo, G., Brito, A., and Barquín, J. (2005). Impactos provocados por los escapes de peces de las jaulas de cultivos marinos en Canarias. Vieraea 33, $449-454$.

Hammer, Ø., Harper, D. A. T., and Ryan, P. D. (2001). Past: paleontological statistics software package for education and data analysis. Palaeontol. Electronica 4, 1-9.

Hegrenes, S. (2001). Diet-induced phenotypic plasticity of feeding morphology in the orangespotted sunfish, Lepomis humilis. Ecol. Freshw. Fish 10, 35-42. doi: 10.1034/j.1600-0633.2001.100105.x

Koumoundouros, G., Ashton, C., Sfakianakis, D. G., Divanach, P., Kentouris, M., Anthwal, N., et al. (2009). Thermally induced phenotypic plasticity of swimming performance in European sea bass Dicentrarchus labrax juveniles. J. Fish Biol. 74, 1309-1322. 
Kuparinen, A., Garcia de Leaniz, C., Consuegra, S., and Merilä, J. (2009). Growthhistory perspective on the decreasing age and size at maturation of exploited Atlantic salmon. Mar. Ecol. Prog. Ser. 376, 245-252. doi: 10.3354/meps07789

Lorenzen, K., Beveridge, M. C. M., and Mangel, M. (2012). Cultured fish: integrative biology and management of domestication and interactions with wild fish. Biol. Rev. 87, 639-660. doi: 10.1111/j.1469-185x.2011.00215.x

Loy, A., Boglione, C., Gagliardi, F., Ferrucci, L., and Cataudella, S. (2000). Geometric morphometrics and internal anatomy in sea bass shape analysis (Dicentrarchus labrax L, Moronidae). Aquaculture 186, 33-44. doi: 10.1016/ s0044-8486(99)00366-x

Manly, B. F. J. (1985). The Statistics of Natural Selection on Animal Populations. London: Chapman and Hall.

Marcil, J., Swain, D. P., and Hutchings, J. A. (2006). Countergradient variation in body shape between two populations of Atlantic cod (Gadus morhua). Proc. Biol. Sci. 273, 217-223. doi: 10.1098/rspb.2005.3306

Marco-Rius, F., Caballero, P., Morán, P., and Garcia de Leaniz, C. (2012). And the last shall be first: heterochrony and compensatory marine growth in sea trout (Salmo trutta). PLoS One 7:e45528. doi: 10.1371/journal.pone.0045528

Marco-Rius, F., Caballero, P., Morán, P., and Garcia de Leaniz, C. (2013). Mixedeffects modelling of scale growth profiles predicts the occurrence of early and late fish migrants. PLoS One 8:e61744. doi: 10.1371/journal.pone.0061744

McArdle, B. H., and Anderson, M. J. (2001). Fitting multivariate models to community data: a comment on distance-based redundancy analysis. Ecology 82, 290-297. doi: 10.1890/0012-9658(2001)082[0290:fmmtcd]2.0.co;2

Navarro-Martín, L., Blázquez, M., Viñas, J., Joly, S., and Piferrer, F. (2009). Balancing the effects of rearing at low temperature during early development on sex ratios, growth and maturation in the European sea bass (Dicentrarchus labrax).: limitations and opportunities for the production of highly femalebiased stocks. Aquaculture 296, 347-358. doi: 10.1016/j.aquaculture.2009.07. 022

Naylor, R., Hindar, K., Fleming, I. A., Goldburg, R., Williams, S., Volpe, J., et al. (2005). Fugitive salmon: assessing the risks of escaped fish from net-pen aquaculture. Bioscience 55, 427-437. doi: 10.1641/0006-3568(2005)055[0427: fsatro] 2.0.co; 2

Olsen, R. E., and Skilbrei, O. T. (2010). Feeding preference of recaptured Atlantic salmon Salmo salar following simulated escape from fish pens during autumn. Aquac. Environ. Interact. 1, 167-174. doi: 10.3354/aei00015

Pakkasmaa, S., and Piironen, J. (2001). Morphological differentiation among local trout (Salmo trutta) populations. Biol. J. Linn. Soc. 72, 231-239. doi: 10.1111/j. 1095-8312.2001.tb01313.x

Pérez-Jiménez, A., Guedes, M. J., Morales, A. E., and Oliva-Teles, A. (2007). Metabolic responses to short starvation and refeeding in Dicentrarchus labrax. Effect of dietary composition. Aquaculture 265, 325-335. doi: 10.1016/j. aquaculture.2007.01.021

Price, E. O. (2002). Animal Domestication and Behavior. Wallingford, UK: CABI. 320.

Rogdakis, Y. G., Koukou, K. K., Ramfos, A., Dimitriou, E., and Katselis, G. N. (2011). Comparative morphology of wild, farmed and hatchery-released gilthead sea bream (Sparus aurata) in western Greece. Int. J. Fish. Aquac. 3, $1-9$.

Rubio, V. C., Sánchez, E., and Cerdá-Reverter, J. M. (2010). Compensatory feeding in the sea bass after fasting and physical stress. Aquaculture 298, 332-337. doi: 10.1016/j.aquaculture.2009.10.031

Sahin, T., Akbulut, B., and Aksungur, M. (2000). Compensatory growth in sea bass (Dicentrarchus labrax), sea bream (Sparus aurata) and rainbow trout (Oncorhynchus mykiss). Turk. J. Zool. 24, 81-86.

Schröder, V., and Garcia de Leaniz, C. (2011). Discrimination between farmed and free-living invasive salmonids in Chilean Patagonia using stable isotope analysis. Biol. Invasions 13, 203-213. doi: 10.1007/s10530-010-9802-z
Smith, L. D. (2009). "The role of phenotypic plasticity in marine biological invasions," in Biological Invasions in Marine Ecosystems: Ecological Management and Geographic Perspectives, eds G. Rilov and J. A. Crooks (New York, NY: Springer), 177-202. doi: 10.1007/978-3-540-79236-9_10

Smith, T. B., and Skúlason, S. (1996). Evolutionary significance of resource polymorphisms in fishes, amphibians and birds. Annu. Rev. Ecol. Syst. 27, 111-133. doi: 10.1146/annurev.ecolsys.27.1.111

Teletchea, F., and Fontaine, P. (2012). Levels of domestication in fish: implications for the sustainable future of aquaculture. Fish Fish. 15, 181-195. doi: 10.1111/ faf.12006

Toledo-Guedes, K., Sanchez-Jerez, P., Benjumea, M. E., and Brito, A. (2014). Farming-up coastal fish assemblages through a massive aquaculture escape event. Mar. Environ. Res. 99, 86-95. doi: 10.1016/j.marenvres.2014.03.009

Toledo-Guedes, K., Sanchez-Jerez, P., González-Lorenzo, G., and Brito, A. (2009). Detecting the degree of establishment of a non-indigenous species in coastal ecosystems: sea bass Dicentrarchus labrax escapes from sea cages in Canary Islands (Northeastern Central Atlantic). Hydrobiologia 623, 203-212. doi: 10. 1007/s10750-008-9658-8

Toledo-Guedes, K., Sanchez-Jerez, P., Mora-Vidal, J., Girard, D., and Brito, A. (2012). Escaped introduced sea bass (Dicentrarchus labrax) infected by Sphaerospora testicularis (Myxozoa) reach maturity in coastal habitats off Canary Islands. Mar. Ecol. 33, 26-31. doi: 10.1111/j.1439-0485.2011. 00470.x

Trut, L., Okina, I., and Kharlamova, A. (2009). Animal evolution during domestication: the domesticated fox as a model. Bioessays 31, 349-360. doi: 10.1002/bies.200800070

Valiente, A. G., Ayllon, F., Nuñez, P., Juanes, F., and Garcia-Vazquez, E. (2010). No all lineages are equally invasive: genetic origin and life-history in Atlantic salmon and brown trout acclimated to the Southern Hemisphere. Biol. Invasions 12, 3485-3495. doi: 10.1007/s10530-010-9746-3

Vandeputte, M., Quillet, E., and Chatain, B. (2012). Are sex ratios in wild European sea bass (Dicentrarchus labrax) populations biased? Aquat. Living Resour. 25, 77-81. doi: 10.1051/alr/2012002

Varsamos, S., Diaz, J. P., Charmantier, G., Flik, G., Blasco, C., and Connes, R. (2002). Branchial chloride cells in sea bass (Dicentrarchus labrax) adapted to fresh water, seawater, and doubly concentrated seawater. J. Exp. Zool. 293, 12-26. doi: 10.1002/jez.10099

West-Eberhard, M. J. (1989). Phenotypic plasticity and the origins of diversity. Annu. Rev. Ecol. Syst. 20, 249-278.

Wimberger, P. H. (1992). Plasticity of fish body shape. The effects of diet, development, family and age in two species of Geogphagus (Pisces: Cichlidae). Biol. J. Linn. Soc. 45, 197-218. doi: 10.1111/j.1095-8312.1992. tb00640.x

Zeder, M. A. (2012). "Pathways to animal domestication," in Biodiversity in Agriculture: Domestication, Evolution, and Sustainability, eds P. Gepts, T. R. Famula, R. L. Bettinger, S. B. Brush, A. B. Damania, P. E. McGuire et al. (Cambridge: Cambridge University Press), 227-259. doi: 10.1017/ cbo9781139019514.013

Conflict of Interest: The authors declare that the research was conducted in the absence of any commercial or financial relationships that could be construed as a potential conflict of interest.

Copyright (c) 2021 Toledo-Guedes, Brito and Garcia de Leaniz. This is an open-access article distributed under the terms of the Creative Commons Attribution License (CC BY). The use, distribution or reproduction in other forums is permitted, provided the original author(s) and the copyright owner(s) are credited and that the original publication in this journal is cited, in accordance with accepted academic practice. No use, distribution or reproduction is permitted which does not comply with these terms. 